\title{
Effects of inpatient pulmonary rehabilitation in patients with interstitial lung disease
}

\author{
Patrick Huppmann ${ }^{1,2}$, Bernd Sczepanski3 , Martina Boensch ${ }^{3}$, \\ Sandra Winterkamp ${ }^{3}$, Ursula Schönheit-Kenn³ ${ }^{3}$ Claus Neurohr¹, \\ Juergen Behr ${ }^{4}$ and Klaus Kenn ${ }^{3}$
}

Affiliations: 'Dept of Internal Medicine I, Division of Pulmonary Diseases, Klinikum Grosshadern, Ludwig Maximilians University of Munich, Munich, ${ }^{2}$ Dept of Pulmonology, Klinik Schillerhoehe, Centre for Pulmonology and Thoracic Surgery, Robert-Bosch-Hospital Stuttgart, University Hospital of Tuebingen, Stuttgart-Gerlingen, ${ }^{3}$ Dept of Pneumology, Schoen-Klinik Berchtesgadener Land, Schoenau am Koenigssee, and ${ }^{4}$ University Hospital Bergmannsheil, Ruhr-University Bochum, Bochum, Germany.

Correspondence: K. Kenn, Dept of Pneumology, Schoen Klinik Berchtesgadener Land, Malterhoeh 1, 83471 Schoenau am Koenigssee, Germany. E-mail: kkenndschoen-kliniken.de

ABSTRACT Pulmonary rehabilitation is recommended for patients with chronic lung diseases including idiopathic pulmonary fibrosis according to international guidelines. However, data for patients with interstitial lung disease (ILD) are limited. We examined the effect of an inpatient pulmonary rehabilitation on functional status and quality of life in ILD patients.

We evaluated 402 consecutive ILD patients who were admitted to a specialised pulmonary rehabilitation centre (1999-2010). All patients performed a standardised pulmonary rehabilitation programme including pulmonary function tests, blood-gas analysis, 6-min walk test (6MWT), dyspnoea rating and health-related quality of life questionnaire (the 36-item short-form health survey; SF-36) on admission and discharge.

Mean duration of pulmonary rehabilitation was $30 \pm 1$ days. 6MWT distance improved by $46 \pm 3 \mathrm{~m}$ $(308 \pm 6 \mathrm{~m}$ versus $354 \pm 6 \mathrm{~m} ; \mathrm{p}<0.001)$. Dyspnoea rating did not change. Lung function testing showed marginal improvement of vital capacity $(+1 \pm 0 \% ; \mathrm{p}=0.002)$. The SF-36 questionnaire demonstrated an increase in all eight sub-scores as well as in the physical and mental health summary scores (physical $6 \pm 1$ points, $\mathrm{p}<0.001$; mental health $10 \pm 1$ points, $\mathrm{p}<0.001$ ). Moreover, patients with signs of pulmonary hypertension also benefited from pulmonary rehabilitation.

In a large cohort of patients with ILD, pulmonary rehabilitation had a positive impact on functional status and quality of life. Considering the limited treatment options in this patient population pulmonary rehabilitation appears to be a valuable adjunct therapy.

@ERSpublications

Pulmonary rehabilitation improved functional status and QoL in a large cohort of ILD patients and appears to be a valuable adjunct therapy http://ow.ly/kOGZ2

Received: May 242012 | Accepted after revision: Oct 102012 | First published online: Oct 252012

Conflict of interest: Disclosures can be found alongside the online version of this article at www.erj.ersjournals.com Copyright @ERS 2013 


\section{Introduction}

Interstitial lung diseases (ILDs) comprise a diverse group of diagnoses including, but not limited to, idiopathic pulmonary fibrosis (IPF), acute and chronic interstitial pneumonias, ILD associated with connective tissues diseases (CTD) and sarcoidosis. Pathologically, ILDs are characterised by involvement of the lung parenchyma with varying amounts of inflammation and fibrosis leading to restrictive physiology and impaired gas exchange. Clinically ILDs are characterised by dyspnoea on exertion, limited exercise tolerance and dry cough $[1,2]$. Increasing dyspnoea and decreasing exercise capabilities lead to patients developing disabilities and impairments in their health-related quality of life (HRQL) [1]. Treatment options are often limited, without proven effect on survival and HRQL, and associated with significant risks and side effects [3].

Pulmonary rehabilitation (PR) has been defined as an "evidence-based, multidisciplinary and comprehensive intervention for patients with chronic respiratory disease who are symptomatic and often have decreased daily life activities" [4]. Comprehensive PR programmes involve not only exercise training with aerobic conditioning, strength and endurance training and respiratory therapy, but also educational lectures, nutritional interventions, behaviour modification techniques to improve self-management and physiological support [3].

The American Thoracic Society (ATS)/European Respiratory Society (ERS) consensus report supports the use of PR in the management of chronic respiratory disease regardless of underlying disease [4]. The benefits of PR have been extensively reported in patients with chronic obstructive pulmonary disease (COPD), with the assumption that the recommendations are applicable to subjects with other lung diseases $[4,5]$. Benefits of PR in COPD patients are reported in view of decreased dyspnoea, increased exercise endurance, improved HRQL and reduced healthcare costs [5-9]. However, data supporting PR in patients with ILD are scarce and the effects of PR in patients with ILD are largely unknown. While ventilatory limitation and skeletal muscle dysfunction are present in both COPD and ILD, impaired pulmonary gas exchange and circulatory factors may be more important in ILD patients [10-12].

So far, only a few studies have investigated the impact of inpatient and outpatient PR in ILD patients. Unfortunately, none of these studies included a sufficient number of patients to conclusively demonstrate clinically meaningful benefits. Nevertheless, the authors of the recent official ATS/ERS/Japanese Respiratory Society/Latin American Thoracic Association evidence-based guideline for IPF recommend PR for the majority of IPF patients (weak recommendation, low-quality evidence) [13]. Consequently the authors suggested further investigations. Therefore, the aim of our study was to assess the impact of an inpatient PR in a specialised centre on a large cohort of ILD patients.

\section{Methods}

\section{Patient population and study design}

440 consecutive patients with ILDs, including IPF, collagen vascular disease, occupational lung disease, sarcoidosis, hypersensitivity pneumonitis and other forms of idiopathic interstitial pneumonias, participating in an inpatient PR at Schoen Klinik Berchtesgadener Land (Schoenau am Koenigssee, Germany) between January 1999 and May 2010, were analysed. 402 (91.4\%) patients were included, 38 $(8.6 \%)$ patients were excluded due to acute infectious disease, heart failure, non-compliance, inability to follow the programme or missing data. Diagnoses were made in accordance with the ATS/ERS international consensus classification of idiopathic interstitial pneumonias [14]. Data were obtained from prospectively maintained medical records and computerised databases. The study was performed in accordance with the local board on medical ethics at Ludwig Maximilians University (Munich, Germany).

Patients participated in a standardised inpatient PR programme (the German health system does not currently offer an outpatient PR programme for ILD patients). On admission all patients received a baseline examination including: a full medical history and physical examination; resting ECG; laboratory screening; blood gas analysis; lung function test; six-min walk test (6MWT); dyspnoea-rating with visual analogue scale (VAS) before and after 6MWT; and health status measured by the 36-item short-form health survey (SF-36) questionnaire. The same investigations were performed 1 day before discharge. Admission data were compared to discharge data.

\section{Pulmonary rehabilitation programme}

Patients underwent a standardised inpatient PR programme consisting of: $5 \mathrm{~h}$ of individually tailored and supervised exercise training and $30 \mathrm{~min}$ of breathing exercises that took place four to five times per week; attendance at aerobic sessions with breathing exercises for $30 \mathrm{~min}$, five times per week; and three sessions of group education per week. PR was individualised based on patient status and estimated exercise capabilities. Exercise training involved aerobic (treadmill, stationary bikes or similar apparatus) and resistance training 
(light weights, resistance bands, etc.). Breathing training consisted of breathing techniques (pursued-lipped, controlled, and diaphragmatic breathing), pacing and energy conservation. Intensity and duration of PR were gradually increased to build tolerance and confidence with the goal of reaching maximum tolerated work load during each exercise period. Supplemental oxygen was given to maintain oxygen saturation $>90 \%$ if desaturation was observed.

Education sessions were aimed at promoting self-management and included self-medication, management of infections and exacerbations, dyspnoea, use of oxygen, return to activities of daily living, and maintaining and improving physical function. If needed, patients received psychosocial support.

\section{Assessments}

Spirometry and bodyplethysmography (Master Screen Jaeger, Wuerzburg, Germany) were measured according to ATS/ERS recommendations and results were compared with the predicted normal values from the ATS/ERS [15, 16]. 6MWT was performed according to recommendations of the ATS [17]. Perceived dyspnoea was obtained using the VAS (0-10).

HRQL was evaluated using the SF-36 questionnaire [18]. SF-36 is a 36-item health status questionnaire with eight domains (physical functioning, bodily pain, physical role functioning, general health perceptions, vitality, social-/emotional role functioning, and general mental health) and two component summary scores (physical and mental health, each of which is derived from four of the eight domain scores). SF-36 health survey items were transformed to a 0-100 scale and scales were constructed using the Likert method of summated ratings [19].

Signs of right heart decompensation or failure were obtained from medical records (heart catheterisation (50\% of patients in pulmonary hypertension ( $\mathrm{PH}$ )-group) in referring hospitals and echocardiography in referring hospitals and/or rehabilitation clinic). Patients were considered to be affected by $\mathrm{PH}$, according to ERS guidelines [20], in case of mean pulmonary artery pressure $\geqslant 25 \mathrm{mmHg}$ in right heart catheterisation or at least two of the following echocardiographic parameters: systolic transtricuspid pressure gradient $>35 \mathrm{mmHg}$, peak tricuspid regurgitation velocity $>2.8 \mathrm{~m} \cdot \mathrm{s}^{-1}$, tricuspid annular plane systolic excursion $\leqslant 17 \mathrm{~mm}$, and right atrial surface area $>27 \mathrm{~cm}^{2}$.

\section{Statistical analyses}

Descriptive statistics are reported as mean \pm SEM. Kolmogorov-Smirnov test was used to examine the distribution of data showing that all data conform to a normal distribution. Demographic data between groups were compared using an unpaired t-test. Within-group and between-group changes between or after PR were evaluated using a paired t-test. A statistical software package (SPSS 18.0 for Windows; SPSS Inc., Chicago, IL, USA) was used for all statistical analyses. Reported p-values were two-sided, $\mathrm{p}<0.05$ was considered statistically significant.

\section{Results}

\section{Patient cohorts}

The study population included 402 patients with ILD performing PR. Mean duration for PR was $30 \pm 1$ days. Baseline characteristics are summarised in table 1 . Mean age of participants was $60 \pm 1$ years (range 21-89 years). 202 (50\%) patients had a confirmed pattern of IPF, 21 (5\%) had an idiopathic interstitial pneumonia other than IPF (non-specific interstitial pneumonia, cryptogenic organising pneumonia), 59 (15\%) patients had hypersensitivity pneumonitis, 50 (12\%) patients had sarcoidosis, 24 (6\%) had ILD associated with CTD and 46 (12\%) had ILD of different aetiology that included drug induced or radiogenic fibrosis after bone-marrow transplantation or of unknown origin. 299 (74\%) patients were listed for lung transplantation, 111 (28\%) patients had documented signs of $\mathrm{PH}, 80 \%$ of patients were on long-term oxygen therapy (LTOT), and the mean vital capacity (VC) was $54 \pm 1 \%$ predicted.

\section{Blood gas analysis and lung function parameters}

Complete lung function parameters and blood gas analyses from arterialised capillary blood from the ear lobe on admission and discharge were available in all patients (table 2). Statistically significant improvements were observed before and after PR in blood gas analyses and lung function parameters (table 2).

\section{MWT parameters}

369 pairs of 6MWT from admission and discharge were available, 33 (8\%) were missing due to exacerbation, cardiac failure and call for transplant. Mean \pm SEM (range) baseline 6-min walking distance $(6 \mathrm{MWD})$ on admission was $308 \pm 6 \mathrm{~m}(5-590 \mathrm{~m})$, the post PR baseline on discharge was $354 \pm 6 \mathrm{~m}(10-$ $646 \mathrm{~m}$ ) (table 2, fig. 1). The change was $46 \pm 3 \mathrm{~m}(-146-328 \mathrm{~m}), \sim 15 \%$ of the baseline value $(\mathrm{p}<0.001)$ 


\section{TABLE 1 Patient characteristics on admission}

\begin{tabular}{|c|c|}
\hline \multirow{2}{*}{\multicolumn{2}{|c|}{ Age years }} \\
\hline Age years & \\
\hline$<40$ & $21(5)$ \\
\hline $40-49$ & $56(14)$ \\
\hline $50-59$ & $126(31)$ \\
\hline $60-69$ & $122(30)$ \\
\hline$>70$ & $77(20)$ \\
\hline $\mathrm{BMI} \mathrm{kg} \cdot \mathrm{m}^{-2}$ & $26.7 \pm 0.3$ \\
\hline$<18.5$ & 28 (7) \\
\hline $18.6-25.0$ & $131(33)$ \\
\hline $25.1-30.0$ & $127(32)$ \\
\hline$>30$ & 99 (25) \\
\hline NA & $17(3)$ \\
\hline \multicolumn{2}{|l|}{ Underlying disease } \\
\hline Idiopathic pulmonary fibrosis & $202(50)$ \\
\hline Nonspecific interstitial pneumonia/cryptogenic organising pneumonia & $21(5)$ \\
\hline Hypersensitivity pneumonitis & $59(15)$ \\
\hline Sarcoidosis & $50(12)$ \\
\hline Connective tissue disease & $24(6)$ \\
\hline Radiogenic/drug induced & $11(3)$ \\
\hline Asbestosis/silicosis/beryliosis & $4(1)$ \\
\hline Other & $31(8)$ \\
\hline \multicolumn{2}{|l|}{ Sex } \\
\hline Male & $203(50)$ \\
\hline Female & $199(50)$ \\
\hline \multicolumn{2}{|l|}{ Smoking status } \\
\hline Never-smoker & $200(50)$ \\
\hline Ex-smoker & $165(41)$ \\
\hline Continuing smoker & $12(3)$ \\
\hline NA & $25(6)$ \\
\hline \multicolumn{2}{|l|}{ Long-term oxygen therapy } \\
\hline Yes & $321(80)$ \\
\hline No & $62(15)$ \\
\hline NA & $19(5)$ \\
\hline Vital capacity $\%$ pred & $54 \pm 1$ \\
\hline$>90$ & $24(6)$ \\
\hline $70-89$ & $64(16)$ \\
\hline $50-69$ & $124(31)$ \\
\hline$<50$ & $190(47)$ \\
\hline \multicolumn{2}{|l|}{ Signs of pulmonary hypertension } \\
\hline No & $286(71)$ \\
\hline Yes & $111(28)$ \\
\hline NA & $5(1)$ \\
\hline \multicolumn{2}{|l|}{ Listed for lung transplantation } \\
\hline Yes & $299(74)$ \\
\hline No & $103(26)$ \\
\hline
\end{tabular}

Data are presented as mean \pm SEM or $n(\%)$. BMI: body mass index; NA: not available. $n=402$.

(table 2). 50 (14\%) patients showed a decreasing 6MWD after PR ( $\mathrm{n}=10$ decrease $\geqslant 50 \mathrm{~m}, \mathrm{n}=40$ decrease $<50 \mathrm{~m}$ ) due to various reasons including acute exacerbations and cardiac decompensations. 319 (86\%) patients showed an increase of $6 \mathrm{MWD}$ during PR $(\mathrm{n}=153$ increase 1-50 m, n=103 increase 50-100 m, $\mathrm{n}=47$ increase $101-150 \mathrm{~m}, \mathrm{n}=16$ increase $>151 \mathrm{~m}$ ). VAS pre- and post-exertion did not differ significantly between admission and discharge (table 2).

\section{Health-related quality of life parameters}

350 patients had completed SF-36 questionnaires on admission and discharge, 52 (13\%) were missing. Mean physical health summary score was $31 \pm 1$ points on admission and $37 \pm 1$ points on discharge, mean mental health summary score was $47 \pm 1$ on admission and $57 \pm 1$ on discharge. All admission and discharge sub-scores are displayed in table 2. Analysis of the SF-36 questionnaire demonstrated a significant increase $(\mathrm{p}<0.05)$ in all eight sub-scores as well as in physical and mental health summary scores (physical: $6 \pm 1$, $\mathrm{p}<0.001$; mental $10 \pm 1, \mathrm{p}<0.001$ ) (table 2, fig. 2). 
TABLE 2 Lung function parameters, 6-min walk test (6MWT) and health related quality of life parameters before and after the rehabilitation programme

\begin{tabular}{|c|c|c|c|c|}
\hline & Admission & Discharge & Change & p-value \\
\hline \multicolumn{5}{|l|}{ Lung function parameters ${ }^{\#}$} \\
\hline $\mathrm{PO}_{2} \mathrm{mmHg}$ & $61 \pm 1$ & $63 \pm 1$ & $2 \pm 1$ & 0.012 \\
\hline $\mathrm{PCO}_{2} \mathrm{mmHg}$ & $39 \pm 0$ & $40 \pm 0$ & $1 \pm 0$ & 0.002 \\
\hline VC $\%$ pred & $54 \pm 1$ & $55 \pm 1$ & $1 \pm 0$ & 0.002 \\
\hline TLC \% pred & $65 \pm 1$ & $65 \pm 1$ & $0 \pm 0$ & 0.322 \\
\hline FEV1 \% pred & $55 \pm 1$ & $56 \pm 1$ & $1 \pm 0$ & $<0.001$ \\
\hline \multicolumn{5}{|l|}{ 6MWT and dyspnoea rating } \\
\hline 6MWD m & $308 \pm 6$ & $354 \pm 6$ & $46 \pm 3$ & $<0.001$ \\
\hline Dyspnoea-free walk distance $m$ & $291 \pm 7$ & $343 \pm 7$ & $52 \pm 4$ & $<0.001$ \\
\hline VAS (before exertion) & $3.2 \pm 0.1$ & $3.3 \pm 0.1$ & $0.1 \pm 0.1$ & 0.572 \\
\hline VAS (after exertion) & $6.5 \pm 0.1$ & $6.3 \pm 0.1$ & $-0.2 \pm 0.1$ & 0.176 \\
\hline \multicolumn{5}{|l|}{ Health status $(\mathrm{SF}-36)^{+}$} \\
\hline Physical functioning & $24 \pm 1$ & $29 \pm 1$ & $5 \pm 1$ & $<0.001$ \\
\hline Bodily pain & $60 \pm 2$ & $66 \pm 2$ & $7 \pm 2$ & $<0.001$ \\
\hline Physical role functioning & $12 \pm 2$ & $17 \pm 2$ & $5 \pm 2$ & 0.009 \\
\hline General health perceptions & $29 \pm 1$ & $33 \pm 1$ & $4 \pm 1$ & $<0.001$ \\
\hline Vitality & $32 \pm 1$ & $45 \pm 1$ & $13 \pm 1$ & $<0.001$ \\
\hline Social role functioning & $52 \pm 2$ & $63 \pm 2$ & $11 \pm 2$ & $<0.001$ \\
\hline Emotional role functioning & $49 \pm 3$ & $56 \pm 3$ & $7 \pm 3$ & 0.029 \\
\hline General mental health & $58 \pm 1$ & $67 \pm 1$ & $9 \pm 1$ & $<0.001$ \\
\hline Physical summary score & $31 \pm 1$ & $37 \pm 1$ & $6 \pm 1$ & $<0.001$ \\
\hline Mental summary score & $47 \pm 1$ & $57 \pm 1$ & $10 \pm 1$ & $<0.001$ \\
\hline
\end{tabular}

Data are presented as mean $\pm \mathrm{SEM}$, unless otherwise stated. $\mathrm{PO}_{2}$ : partial oxygen pressure; $\mathrm{PCO}_{2}$ : partial carbon dioxide pressure; VC: vital capacity; TLC: total lung capacity; FEV1: forced expiratory volume in $1 \mathrm{~s}$; 6MWD: 6-min walking distance; VAS: visual analogue scale; SF-36: the 36-item short-form health survey. ${ }^{\#}: \mathrm{n}=402$; ": $\mathrm{n}=369 ;{ }^{+}: \mathrm{n}=350$.

\section{Predictors of change}

Of the variables tested (age, sex, body mass index, smoking history, use of LTOT, baseline forced vital capacity (FVC), baseline 6MWD and baseline VAS), only baseline 6MWD was a significant predictor of change in $6 \mathrm{MWD}$, but not for change in improvement of SF-36 scores. The improvement in 6MWD was smaller the higher the baseline 6MWD was $(\mathrm{p}<0.01)$ (fig. 3).

\section{Effect of pulmonary hypertension on outcome of PR}

Baseline demographic characteristics from patients with and without signs of $\mathrm{PH}$ were statistically indistinguishable. Lung function parameters (blood gas analysis and lung volumes) improved during PR in the non-PH group, whereas in ILD patients with signs of PH only VC improved (table 3). Patients not affected by PH had significant improvements in the physical and mental health sub-scores of SF-36, while in patients with signs of PH only significant improvements in the mental health sub-scores could be observed.

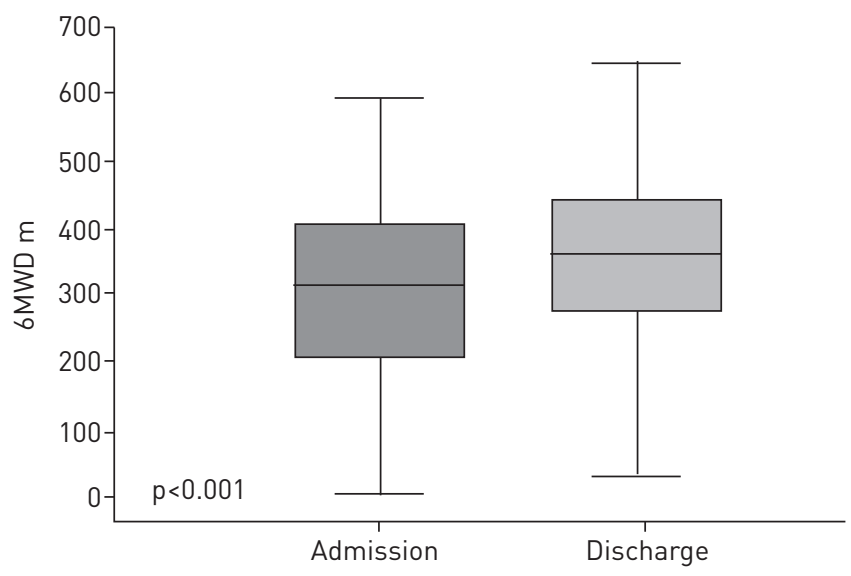

FIGURE 1 The mean \pm SEM 6-min walk test $(6 \mathrm{MWT})$ on admission $(308 \pm 6 \mathrm{~m})$ and discharge $(354 \pm 6 \mathrm{~m})$ gave a change of $+46 \pm 3$ m (15\%). Box- and whisker-plots show comparison of 6MWT on admission and on discharge. The horizontal line displays the median, the box-edges show the 25th and 75th percentiles and the whiskers show the smallest and highest value within 1.5 box lengths from the box. 6MWD: 6-min walking distance. 

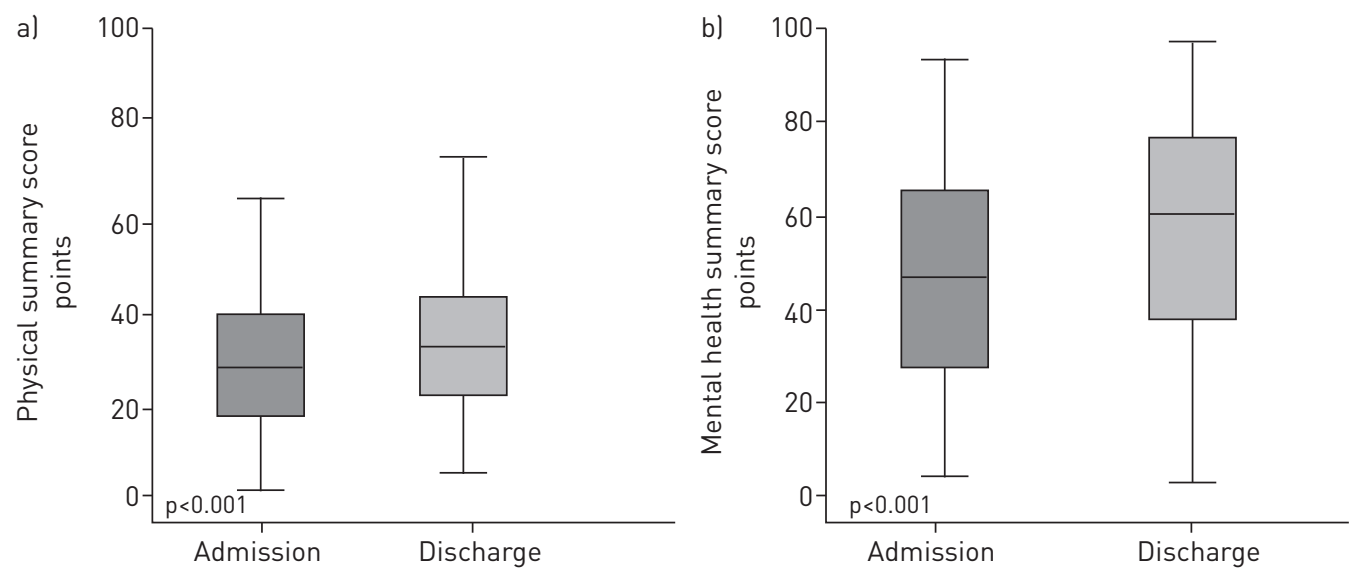

FIGURE 2 Health-related quality of life on admission and on discharge. Box- and whisker-plots show comparison of a) physical summary score and b) mental health summary score of the 36-item short-form health survey (SF-36) questionnaire on admission to and on discharge from hospital. A mean \pm SEM change of $6 \pm 1$ points was observed in the physical summary score (from $31 \pm 1$ to $37 \pm 1$ ) and a change of $10 \pm 1$ points in the mental health summary score (from $47 \pm 1$ to $57 \pm 1$ ) The horizontal line displays the median, the box-edges show the 25th and 75th percentiles and the whiskers show the smallest and highest value within 1.5 box lengths from the box.

6MWD on admission were significantly lower in patients with signs of $\mathrm{PH}$ compared to those without signs of $\mathrm{PH}(277 \pm 12 \mathrm{~m}$ versus $322 \pm 8 \mathrm{~m} ; \mathrm{p}=0.001)$. On discharge, both groups showed a significant improvement $(\mathrm{p}<0.001)$ ( $\mathrm{PH}: 313 \pm 12 \mathrm{~m}$ versus non- $\mathrm{PH}: 370 \pm 7 \mathrm{~m})$. However, patients with signs of $\mathrm{PH}$ had a smaller absolute increase in $6 \mathrm{MWD}$ compared to patients without signs of $\mathrm{PH}(36 \pm 6 \mathrm{~m}$ versus $48 \pm 3 \mathrm{~m} ; \mathrm{p}=0.045$ ) (table 3).

\section{Discussion}

We evaluated the impact of an inpatient PR programme in a specialised centre on patients with ILD. Our data demonstrate that PR is beneficial in these patients and appears to be a valuable adjunct therapy. Our results show small but statistically significant improvements in lung function parameters before and after PR. More importantly, significant improvements in both functional status and HRQL were observed. This benefit was seen regardless of age, sex, underlying disease or baseline pulmonary function. Additionally, our data suggest that patients with signs of $\mathrm{PH}$ also benefited from an inpatient PR; however, to a smaller extent. This finding is in line with Mereles et al. [21], who showed that even patients with advanced pulmonary arterial hypertension can improve with specialised PR.

PR is widely accepted for patients with COPD since many studies demonstrated benefits regarding exercise endurance, decreasing dyspnoea, improvement of HRQL and reducing healthcare costs [5]. There is a good
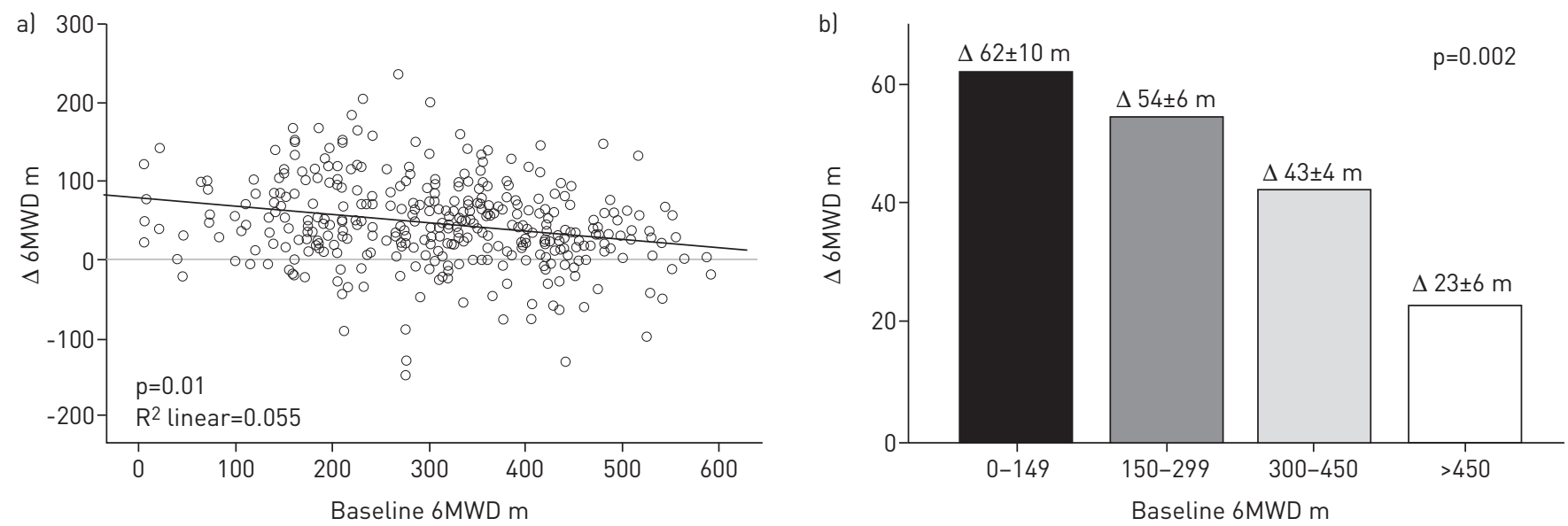

FIGURE 3 Baseline 6-min walking distance (6MWD) is a predictor for improvement during pulmonary rehabilitation. a) Points display the difference $(\Delta)$ in 6MWD between admission and discharge dependent on the 6MWD on admission. b) The mean change in the 6MWD between admission and discharge dependent on baseline 6MWD. 
TABLE 3 Lung function parameters, 6-min walk test (6MWT) and health-related quality of life parameters for patients with and without signs of pulmonary hypertension $(\mathrm{PH})$ before and after the rehabilitation programme

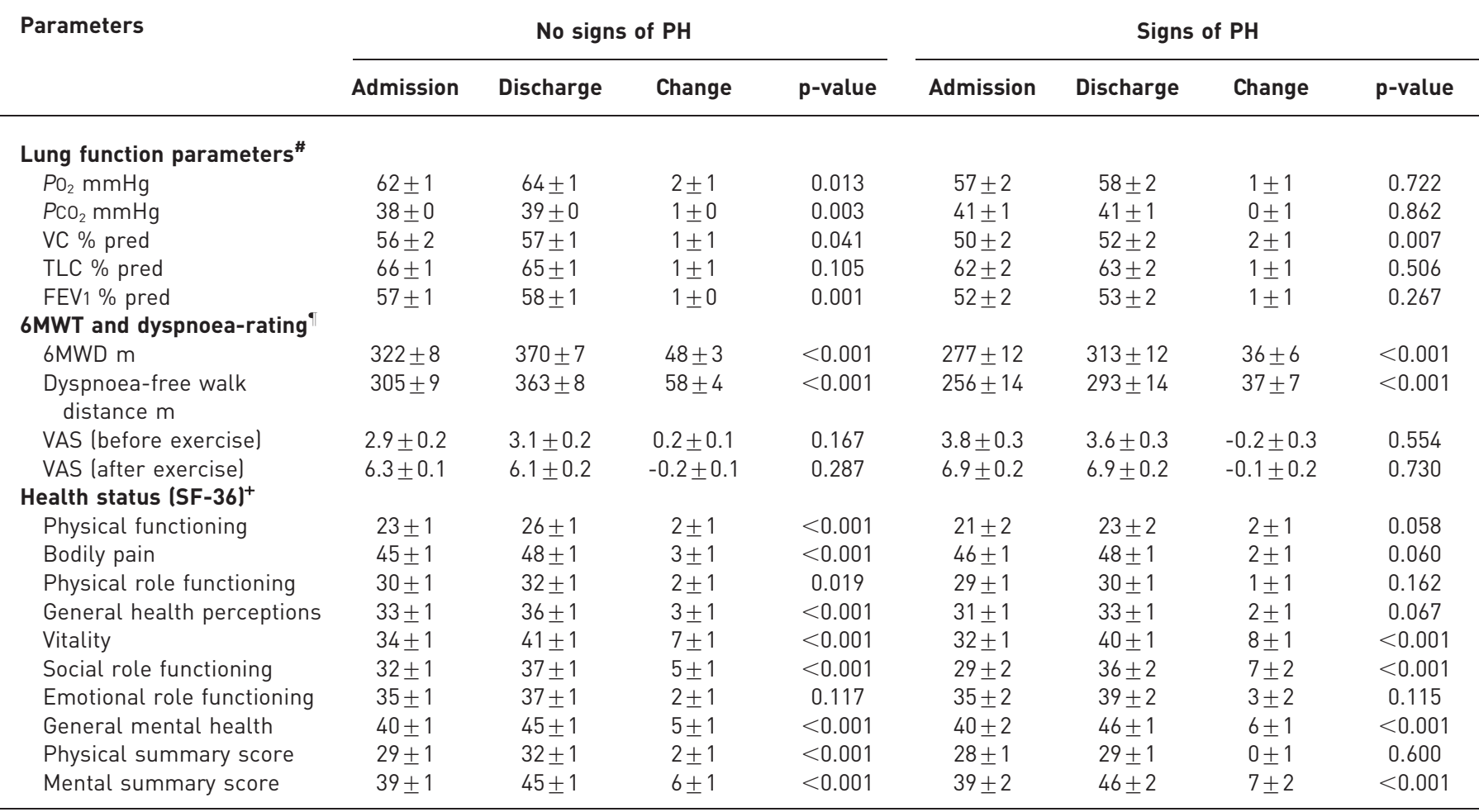

Data are presented as mean $\pm \mathrm{SEM}$, unless otherwise stated. $\mathrm{PO}_{2}$ : partial oxygen pressure; $\mathrm{PCO}_{2}$ : partial carbon dioxide pressure; VC: vital capacity; TLC: total lung capacity; FEV1: forced expiratory volume in $1 \mathrm{~s}$; 6MWD: 6-min walking distance; VAS: visual analogue scale; SF-36: the 36-item short-form health survey. ${ }^{\#}: n=402 ;{ }^{\circ}: n=369 ;{ }^{+}: n=350$.

rationale for the use of PR also in patients with ILD. Exercise training improves aerobic capacity, muscle strength and flexibility, contributing to less dyspnoea on exertion and to improvement of functional status. Additionally PR has psychosocial benefits that help patients understand their disease and may mitigate anxiety and depression [22]. Due to these advantages it is widely supposed that patients with ILD might profit from PR. However, only a few studies have investigated the effect of PR in this population and most of the published studies evaluated outpatient PR programmes.

We observed a small, statistically significant improvement of blood gas analysis and lung function parameters, which is in line with other published studies [10, 23]. Although these improvements are statistically significant, their clinical relevance is probably negligible. With respect to the underlying pathophysiology this is also concordant to our expectations regarding the potential effects of a 30-day PR programme.

We demonstrate a significant improvement in $6 \mathrm{MWD}$ of $46 \pm 3 \mathrm{~m}, \sim 15 \%$ of the baseline value. Between different groups of underlying diseases of ILD (e.g. IPF, hypersensitivity pneumonitis) we could not document significantly different improvements in 6MWD before and after PR. Only a few studies have investigated the effect of PR on the 6MWD in ILD patients so far; in all of them PR was performed as an outpatient programme. NishiYAma et al. [23] observed a PR effect of $46 \mathrm{~m}$ in 6MWD, whilst, HollaND et al. [24] reported a mean increase in the $6 \mathrm{MWD}$ of $35 \mathrm{~m}$ in ILD patients and of $25 \mathrm{~m}$ in a subgroup analysis of 34 patients with IPF. FERREIRA et al. [22] measured an average increase of $56 \mathrm{~m}$ in their study with 113 ILD patients and SWIGRIS et al. [25] documented an improvement of $61 \mathrm{~m}$ in 6MWD in their study of $21 \mathrm{IPF}$ patients. In contrast, KozU et al. [10] found only an increase of $16 \mathrm{~m}$ in 6MWD in 36 IPF patients. Based on lung function parameters, patients included in all of these studies showed less advanced ILD with a lower proportion of LTOT when compared with our study population (table 4).

The minimal clinically important difference (MCID) for the 6MWT in ILD is still under debate. In COPD patients a distance of $54 \mathrm{~m}$ has been identified for the MCID, although more recently this value has been questioned and the threshold for MCID may be lower in this group (PUHAN et al. [26] suggest $35 \mathrm{~m}$ ) [27]. 
TABLE 4 Comparison of results with recent published literature

\begin{tabular}{lccccc} 
& Holland [24] & NishiYama [23] & Ferreira [22] & SwigRIS [25] & Present study \\
\hline Publication year & 2008 & 2008 & 2009 & 2011 & 2013 \\
Subjects n & 57 & 28 & 99 & 21 & 402 \\
Inpatient/outpatient & Outpatient & Outpatient & Outpatient & Outpatient & Inpatient \\
ILD group & ILD & IPF only & ILD & IPF only & ILD \\
Age years & 67 & $68 \pm 9$ & 66 & $71.5 \pm 7.4$ & $60 \pm 1$ \\
Time of PR & 8 weeks & 8 weeks & 8 weeks & 8 weeks & $30 \pm 1$ days \\
VC \% pred & 75 & $66 \pm 13$ & 62 & $73 \pm 22$ & $54 \pm 1$ \\
Po mmHg & NA & $80 \pm 12$ & NA & NA & $61 \pm 1$ \\
LTOT \% & NA & Cl & 65 & NA & 80 \\
$\Delta$ 6MWD m & 35 & 46 & 56 & $61 \pm 41$ & $46 \pm 3$ \\
\hline
\end{tabular}

Data are presented as mean $\pm \mathrm{SEM}$, unless otherwise stated. ILD: interstitial lung disease; PR: pulmonary rehabilitation; VC: vital capacity; $\mathrm{PO}_{2}$ : partial oxygen pressure; LTOT: long-term oxygen therapy; $\triangle 6 \mathrm{MWD}$ : change in 6-min walking distance; IPF: idiopathic pulmonary fibrosis; $\mathrm{NA}$ : data not available; $\mathrm{Cl}$ : contraindication.

Based on a large cohort of 822 IPF patients the MCID for the 6MWD was calculated to be $24-45 \mathrm{~m}$, depending on the statistical method employed [28]. This is in line with the previous studies of HollanD et al. [29] who assumed an improvement of 6MWD in the range 29-34 $\mathrm{m}$ to be clinically relevant in people with parenchymal lung disease, and SwIGRIS et al. [30] who calculated the MCID for 6MWD to be $28 \mathrm{~m}$. Thus, the improvement in 6MWD of $46 \mathrm{~m}$ is among the highest MCID discussed and reflects a meaningful increase in exercise capacity in our patients. In contrast to the previously cited study populations, we have to highlight that 299 of our patients $(74 \%)$ were listed for lung transplantation. This clearly demonstrates the efficacy of inpatient PR even in a patient-group with end stage ILD.

In our study we could show that baseline 6MWD was a significant predictor of change in 6MWD after PR. Interestingly, and in concordance with data from COPD patients, the lower the baseline the more likely the patient was to improve. Lower 6WMD baselines were associated with lower FVC baselines and total lung capacity and the use of LTOT. This observation emphasises that patients, especially those with severe impairments, may substantially benefit from PR. This observation is flawed slightly by the fact that patients with signs of PH had lower baseline 6MWD and showed less improvement. However, even in this subgroup the observed increase in 6MWD was still within the range of the assumed MCID.

Our observation, that lower baseline 6MWD predicts higher benefits from PR are in line with data published by FerreIra et al. [22]. Nonetheless, PR is also effective in patients with high baseline 6MWD. This is confirmed by our data showing improvements in $6 \mathrm{MWD}$, which are in the range of the MCID, even in patients with high baseline 6MWD (fig. 3b).

Dyspnoea rating, using VAS before and after exertion, did not change significantly in the current study. This is contrary to experiences from COPD studies that show improved dyspnoea ratings [5]. We speculate that ILD patients walking at their highest possible capacities achieve their dyspnoea maximum more rapidly, in contrast to COPD patients, independent of the distance walked. However, due to conflicting data from different studies, dyspnoea rating is still under debate in IPF patients [10, 22-25].

In addition to increased exercise capacity another important aspect of PR is an improvement in HRQL. We observed a pattern of poor health status measured by the SF-36 questionnaire that is well established in patients with ILD [31]. In the current study we noticed a statistically significant improvement in both summary scores (physical and mental health) of SF-36 as well as in all eight sub-scores. Clinically meaningful changes in SF-36 questionnaire have not been firmly established in patients with ILD, but in general, a 5-point increase in SF-36 summary score is supposed to indicate a MCID [32]. Therefore, our data show a significant and clinically important improvement in all sub- and summary-scores of SF-36. Our observation is in concordance with some published studies $[8,23,31,33]$, while others did not detect any influence of PR in HRQL [10, 24, 25]. NAJI et al. [31] demonstrated in their group of ILD patients a significant reduction in anxiety and depression after completing PR. Some investigations, including ours, have noted that PR participants perceive greater improvements in mental health than in physical aspects. This is more interesting regarding the aspect that dyspnoea is the most important factor determining HRQL in ILD patients [34]. Although in our study the dyspnoea rating during the 6MWT did not differ between admission and discharge, we speculate that improved physical ability resulted in a feeling of better health, since before PR most patients claimed to have decreasing physical ability. 
There are some important limitations that warrant attention. First, the current study was an open clinical nonrandomised study without a control group. Secondly, due to the long duration of the study an influence of changes, regarding staff or training modalities as well as training effects of the team, cannot be excluded. Thirdly, although the 6MWT was performed by specially trained medical staff and in strict accordance with current standards, it was obtained by several examiners. Finally, some patients were enrolled after an acute deterioration or after listing for lung transplantation, which may have introduced a selection bias. The observation period in this study was restricted to the active PR phase. Long-term follow-up data are not available, consequently, the long-term effect of PR remains unknown. Further data concerning the costeffectiveness of such an inpatient PR programme are lacking.

Despite these limitations our study provides robust data demonstrating that inpatient PR is beneficial for ILD patients. We were able to show statistically and clinically significant improvements in exercise capacity and HRQL in physical, as well as in mental health, in a large cohort of ILD patients. These benefits are even more pronounced in patients with poorer functional status at baseline. Moreover, ILD patients with signs of $\mathrm{PH}$ also benefit significantly from PR.

Considering the limited treatment options in this patient population PR appears to be a valuable adjunct therapy that should be offered to ILD patients. Further research should focus on controlled trials and on the durability of the effects observed here.

\section{Acknowledgements}

The authors want to thank E. Fischenbeck (Schoen-Klinik, Prien am Chiemsee, Germany) for her extensive help with calculation of the SF-36 values and F. Ihle (Dept. of Internal Med I, Klinikum Grosshadern, Ludwig Maximilians University of Munich, Munich, Germany) for her valuable explanations and comments for SF-36 analysis. Last but not least we thank our patients and all participating doctors, physiotherapists and nurses at Schoen Klinik Berchtesgadener L (Schoenau am Koenigssee, Germany) for their excellent contribution to this study.

\section{References}

1 Collard HR, King TE Jr, Bartelson BB, et al. Changes in clinical and physiologic variables predict survival in idiopathic pulmonary fibrosis. Am J Respir Crit Care Med 2003; 168: 538-542.

2 Flaherty KR, Andrei AC, Murray S, et al. Idiopathic pulmonary fibrosis: prognostic value of changes in physiology and six-minute-walk test. Am J Respir Crit Care Med 2006; 174: 803-809.

3 Holland AE, Hill C. Physical training for interstitial lung disease. Cochrane Database Syst Rev 2008; 4: CD006322.

4 Nici L, Donner C, Wouters E, et al. American Thoracic Society/European Respiratory Society statement on pulmonary rehabilitation. Am J Respir Crit Care Med 2006; 173: 1390-1413.

5 Lacasse Y, Goldstein R, Lasseron TJ, et al. Pulmonary rehabilitation for chronic obstructive pulmonary disease. Cochrane Database Syst Rev 2006; 4: CD003793.

6 Niedermann MS, Clemente PH, Fein AM, et al. Benefits of a multidisciplinary pulmonary rehabilitation program. Improvements are independent of lung function. Chest 1991; 99: 798-804.

7 Laviolette L, Bourbeau J, Bernard S, et al. Assessing the impact of pulmonary rehabilitation on functional status of COPD. Thorax 2008; 63: 115-121.

8 Verrill D, Barton C, Beasley W, et al. The effects of short-term and long-term pulmonary rehabilitation on functional capacity, perceived dyspnoea and quality of life. Chest 2005; 128: 673-683.

9 Ries AL, Make BJ, Lee SM, et al. The effects of pulmonary rehabilitation in the national emphysema treatment trial. Chest 2005; 128: 3799-3809.

10 Kozu R, Senjyu H, Jenkins SC, et al. Differences in response to pulmonary rehabilitation in idiopathic pulmonary fibrosis and chronic obstructive disease. Respiration 2011; 81: 196-205.

11 Nishyiama O, Taniguchi H, Kondoh Y, et al. Quadriceps weakness is related to exercise capacity in idiopathic pulmonary fibrosis. Chest 2005; 127: 2028-2033.

12 Spriut MA, Thomeer MJ, Gosselink R, et al. Skeletal muscle weakness in patients with sarcoidosis and its relationship with exercise intolerance and reduced health status. Thorax 2005; 60: 32-38.

13 Raghu G, Collard HR, Egan JJ, et al. An official ATS/ERS/JRS/ALAT statement: idiopathic pulmonary fibrosis: evidence-based guidelines for diagnosis and management. Am J Respir Crit Care Med 2011; 183: 788-824.

14 American Thoracic Society/European Respiratory Society international multidisciplinary consensus classification of the idiopathic interstitial pneumonias. Am J Respir Crit Care Med 2002; 165: 277-304.

15 Miller MR, Hankinson J, Brusasco V, et al. Standardisation of spirometry. Eur Respir J 2005; 26: 319-338.

16 Wanger J, Clausen JL, Coates A, et al. Standardisation of the measurement of lung volumes. Eur Respir J 2005; 26: $511-522$.

17 ATS statement: guidelines for the six-minute walk test. Am J Respir Crit Care Med 2002; 166: 111-117.

18 Ware JE, Snow KK, Kosinski M, et al. SF-36 Health Survey: Manual and Interpretation Guide (vol. 3). Boston, The Health Institute, New England Medical Centre, 1994; pp. 4-6.

19 Ware JE Jr, Hays RD. Methods for measuring patient satisfaction with specific medical encounters. Med Care 1988; 26: 393-402.

20 Galie N, Hoeper MM, Humbert M, et al. Guidelines for the diagnosis and treatment of pulmonary hypertension. Eur Respir J 2009; 34: 1219-1263.

21 Mereles D, Ehlken N, Kreuscher S, et al. Exercise and respiratory training improve exercise capacity and quality of life in patients with severe chronic pulmonary hypertension. Circulation 2006; 114: 1482-1489.

22 Ferreira A, Garvey C, Connors GL, et al. Pulmonary rehabilitation in interstitial lung disease: benefits and predictors of response. Chest 2009; 135: 442-447. 
Nishiyama O, Kondoh Y, Kimura T, et al. Effects of pulmonary rehabilitation in patients with idiopathic pulmonary fibrosis. Respirology 2008; 13: 394-399.

24 Holland AE, Hill CJ, Conron M, et al. Short term improvement in exercise capacity and symptoms following exercise training in interstitial lung disease. Thorax 2008; 63: 549-554.

25 Swigris JJ, Fairclough DL, Morrison M, et al. Benefits of pulmonary rehabilitation in idiopathic pulmonary fibrosis. Respir Care 2011; 56: 783-789.

26 Puhan MA, Mador MJ, Held U, et al. Interpretation of treatment changes in 6-minute walk distance in patients with COPD. Eur Respir J 2008; 32: 637-643.

27 Redelmeier DA, Bayoumi AM, Goldstein RS, et al. Interpreting small differences in functional status: the six minute walk test in chronic lung disease patients. Am J Respir Crit Care Med 1997; 155: 1278-1282.

28 du Bois RM, Weycker D, Albera C, et al. Six-minute-walk test in idiopathic pulmonary fibrosis: test validation and minimal clinically important difference. Am J Respir Crit Care Med 2011; 183: 1231-1237.

29 Holland AE, Hill CJ, Conron M, et al. Small changes in six-minute walk distance are important in diffuse parenchymal lung disease. Respir Med 2009; 103: 1430-1435.

30 Swigris JJ, Wamboldt FS, Behr J, et al. The six minute walk in idiopathic pulmonary fibrosis: longitudinal changes and minimum important difference. Thorax 2010; 65: 173-177.

31 Naji NA, Connor MC, Donelly SC, et al. Effectiveness of pulmonary rehabilitation in restrictive lung disease. J Cardiopulm Rehabil 2006; 26: 237-243.

32 Swigris JJ, Gould MK, Wilson SR. Health related quality of life among patients with idiopathic pulmonary fibrosis Chest 2005; 127: 284-294.

33 Jastrzebski D, Gumola A, Gawlik R et al. Dyspnoea and quality of life in patients with pulmonary fibrosis after six weeks of respiratory rehabilitation. J Physiol Pharmacol 2006; 57: Suppl. 4, 139-148.

34 Nishiyama O, Taniguchi H, Kondoh Y, et al. Health-related quality of life in patients with idiopathic pulmonary fibrosis. What is the main contributing factor? Respir Med 2005; 99: 408-414. 